\title{
Learning theory and its application to the use of social media in medical education
}

\author{
Leslie Flynn, ${ }^{1}$ Alireza Jalali, ${ }^{2}$ Katherine A Moreau ${ }^{3}$
}

${ }^{1}$ Faculty of Health Sciences, Queen's University, Kingston, Ontario, Canada

${ }^{2}$ Faculty of Medicine, University of Ottawa, Ottawa, Ontario,

Canada

${ }^{3}$ Department of Pediatrics, University of Ottawa, Ottawa, Ontario, Canada

\section{Correspondence to} Dr Leslie V Flynn, Faculty of Health Sciences, Queen's University, 18 Barrie St, Kingston, Ontario, Canada K7L 3N6; flynnl@queensu.ca

Received 4 March 2015 Revised 11 June 2015 Accepted 23 July 2015 Published Online First 14 August 2015

\section{SLinked}

- http://dx.doi.org/10.1136/ postgradmedj-2014-133230

- http://dx.doi.org/10.1136/ postgradmedj-2015-133300

- http://dx.doi.org/10.1136/ postgradmedj-2015-133353

- http://dx.doi.org/10.1136/ postgradmedj-2015-133612

- http://dx.doi.org/10.1136/

postgradmedj-2015-133686

CrossMark

To cite: Flynn L, Jalali A, Moreau KA. Postgrad Med J 2015;91:556-560.

\begin{abstract}
Background There is rapidly increasing pressure to employ social media in medical education, but a review of the literature demonstrates that its value and role are uncertain.
\end{abstract}

Objective To determine if medical educators have a conceptual framework that informs their use of social media and whether this framework can be mapped to learning theory.

Methods Thirty-six participants engaged in an iterative, consensus building process that identified their conceptual framework and determined if it aligned with one or more learning theories.

Results The results show that the use of social media by the participants could be traced to two dominant theories-Connectivism and Constructivism. They also suggest that many medical educators may not be fully informed of these theories.

Conclusions Medical educators' use of social media can be traced to learning theories, but these theories may not be explicitly utilised in instructional design. It is recommended that formal education (faculty development) around learning theory would further enhance the use of social media in medical education.

\section{INTRODUCTION}

Present-day medical students and residents are predominantly members of the demographic group that is known as 'millennial learners'. This group has also been referred to as 'generation Y', the 'net generation' and 'digital natives'. 'They are the first generation of learners to have grown up with the internet. $^{2}$ It is this generation that has used and popularised Web V.2.0, ${ }^{2}$ a term that was originally used by Tim O'Reilly to describe network technologies and services that bring a user focus to the creation and construction of the content and functionality of the platforms. ${ }^{3}$

The 'net generation' is described as a cohort that is digitally literate, constantly connected to others, 'immediate' in nature, experiential learners and socially centred beings. ${ }^{1}$ Today's medical students expect that their teachers will effectively use information technologies to enhance their learning. ${ }^{14}$

In turn, the medical education community and its associated literature increasingly hold the same expectation of the medical educator. Repeatedly it is identified that, given the nature of the learners and their ubiquitous use of social media, social media should be incorporated into teaching and learning in medical education. ${ }^{1} 2$ 4-6

However, despite the recognition of this new generation of learners and the imperative to meet their learning needs, there is a paucity of information that gives medical educators direction as to how and when to appropriately incorporate social media in their teaching. Indeed, the uncertainty regarding the benefit remains unclear and, although the use of social media in medicine has increased substantially, "its utility for enhancing learning remains poorly understood". ${ }^{7}$ Further, a review of the published literature on social media use in medical education led to the conclusion that there is "a lack of high-quality evidence, infrequent assessment of skill or behaviour-based outcomes, and no assessment of patient-based outcomes in the studies".5 More concerning is the finding that "without structure, social media can negatively impact student learning", and yet "it is the instructor who must lead effective ways to implement devices in learning". 8

The use of social media in medical education should have the goal of promoting learning, and it is well established that learning theories are fundamental to the development of sound pedagogy. By understanding the theories, educators will know why specific practices work and they will create activities that will lead students to achieve the desired learning outcomes. There are a large number of learning theories, all of which are based on several fundamental criteria. These are: (1) a set of explicit assumptions about learning; (2) explicit definitions of key terms; (3) specific principles derived from assumptions that can be tested; and (4) explanations of the underlying psychological dynamics of events that influence learning. ${ }^{9}$

This paper reports on a workshop from the Social Media Summit examining how learning theory should inform the use of social media in medical education. Based on the medical education literature, ${ }^{10}$ we proposed that, despite the lack of an overt adoption of a theoretical framework, medical educators do adhere to a conceptual framework as they approach their teaching, and particularly when engaged in introducing an innovation. The workshop objectives were to (1) examine participants' beliefs, frameworks, values and approaches to education (their conceptual framework) that inform how they use social media; (2) demonstrate how their conceptual frameworks map to learning theory; and (3) discuss how understanding learning theory is essential to the effective use of social media in medical education.

\section{METHODS}

\section{Participants}

Thirty-six participants from the 83 in-person members of the Social Media Summit self-selected to participate in this facilitated workshop session. 


\section{Process and data analysis}

We conducted the workshop in seven steps:

Step 1. We reviewed the literature and established questions to provide a framework for the workshop (listed in box 1).

Step 2. We reviewed the literature regarding social media and the importance of learning theory in the design and delivery of education with the participants.

Step 3. We engaged the participants in a personal examination of their educational philosophy using the questions listed in box 2. This was conducted because it is well documented that an educator approaches education in a manner that is consistent with a theoretical framework. ${ }^{11}$ The questions examined their beliefs about teaching and learning (epistemology), framework for representing knowledge (ontology), values (axiology) and approaches to education (methodology).

Step 4. We posted the questions on an online programme using a cloud-based software entitled Socrative, which is an open access programme found at http://www.socrative.com. This site electronically recorded the individual participant responses during the workshop.

Step 5. Using this software, we then displayed and reviewed the responses with the participants to identify common themes for each question in box 2. We discussed epistemology as their view of, or beliefs about, the nature of knowledge; ontology as one's framework for representing knowledge and how it is used to build theory; axiology as the study of values in teaching and learning and how one's values direct them in their development of their philosophy or theory; and methodology as the theoretical underpinning for understanding which best practices can be applied in an educational situation.

Step 6. We matched the educational philosophies of the individuals to learning theories, and in particular their use of social media in education. We asked participants to begin by selecting the learning theory or theories that best reflect their philosophy and to choose those that are applicable to their use of social media. We guided participants to a list of seven relevant learning theories (connectivism, community of practice, situated cognition/situated learning, discovery learning, social development of theory, experiential learning, activity theory and multimodality theory) and three online reference sites were provided (http://edudemic.com/ wp-content/uploads/2013/06/learningtheories-full.jpg, http://www. teachersgarden.com/professionalresources/learningtheorists.html and the more detailed reference http://www.Learning-theories. com/paradigms).The task for the individual participants was to

Box 1 The five inquiry questions set by the workshop facilitators to frame the $2 \mathrm{~h}$ facilitated session

1. What is the implicit theory underpinning the work of clinical teachers?

2. How can this implicit theory be mapped onto established theories of epistemology, ontology, axiology and methodology (understanding, being, valuing and acting)?

3. Are there established educational theories that align with individual participant's identified ways of understanding, being, valuing and acting in educational contexts?

4. Is there a set of educational theories that can capture the implicit theories of practising clinical educators?

5. How do social media support the enactment of educational theories? link their educational philosophy with one or two learning theories that reflected their conceptual framework.

Step 7. We asked participants to work as a group to examine their choices of learning theories and come to consensus as a group on the two or three theories that they deemed most clearly represented their collective approach to their use of social media in medical education.

\section{RESULTS}

\section{Participant characteristics}

All 36 participants contributed to the individual online data regarding their conceptual frameworks. Analysis of the relationship of these frameworks to learning theory was carried out individually and then in six working groups to which they were randomly allocated. All six working groups reported their consensus about which learning theories most appropriately reflected how they use social media in education.

\section{Relationship between the participants' conceptual frameworks and learning theories}

The participants' answers to the questions in box $2(n=36)$ were posted on Socrative and reviewed and discussed by the group. We found that the participants identified that they are guided in their work by implicit theory (ie, their educational philosophy) and that these implicit theories can be mapped onto established theories of learning. Furthermore, we found that there are specific theories that align with the participants' ways of understanding, values and methods of teaching in educational contexts, as shown in table 1 . Some participants acknowledged that they had not previously referred to learning theory as they introduced social media into their teaching.

\section{Consensus among the working groups}

Each of the six groups identified Connectivism as a learning theory that was reflected in their use of social media. There was agreement that there was a high degree of both alignment of their educational philosophy with learning theory and a

\section{Box 2 Questions used by participants to explore their} educational philosophy

1. Your concept of learning: What does learning mean to you? What happens in a successful learning situation? (epistemology)

2. Your concept of teaching: What does an ideal teaching situation look like to you? What is your role as the teacher? Are you a coach, a general, an 'evangelist', an entertainer? (epistemology)

3. What strategies do you use to help students/trainees reach the stated learning outcomes? (eg, case studies, group work, simulations, interactive lectures) (ontology)

4. Your interaction with students/trainees: What are your attitudes towards advising and mentoring students/trainees? How would an observer see you interact with students/ trainees? (axiology)

5. Specific examples: How are the values and beliefs noted above realised in educational/training activities/You may discuss course materials, lesson plans, activities, assignments, assessment instruments, etc (methodology) 
Table 1 Results of the consensus of theories identified by the six working groups

\begin{tabular}{|c|c|c|}
\hline Theory & $\begin{array}{l}\text { Number of groups } \\
\text { identifying theory }\end{array}$ & Theory definition \\
\hline Connectivism & 6 & $\begin{array}{l}\text { Explains how internet technologies have created opportunities for learning across online peer networks. Teachers } \\
\text { guide students to information and key answers as needed to support students' learning and sharing }\end{array}$ \\
\hline Social development theory & 3 & $\begin{array}{l}\text { Social interaction is fundamental to learning. Learning occurs in the zone of proximal development-the area between } \\
\text { needed instructor/peer guidance and the learner's ability to function independently }\end{array}$ \\
\hline Communities of practice & 3 & $\begin{array}{l}\text { A process of social learning that occurs when people with a common interest collaborate sharing ideas, strategies, } \\
\text { determining solutions and building innovations }\end{array}$ \\
\hline Cognitive apprenticeship & 1 & $\begin{array}{l}\text { Cognitive apprenticeship attempts to bring tacit processes out into the open. It assumes that people learn from one } \\
\text { another through observation, imitation and modelling }\end{array}$ \\
\hline Discovery learning & 1 & $\begin{array}{l}\text { An inquiry-based theory that believes it is best for learners to discover facts and relationships for themselves by } \\
\text { exploring, problem solving and discovering knowledge experientially }\end{array}$ \\
\hline Self-determination theory & 1 & $\begin{array}{l}\text { A theory that addresses intrinsic and extrinsic motivation. To actualise a learner's inherent potential the social } \\
\text { environment needs to nurture competence, relatedness and autonomy }\end{array}$ \\
\hline Cognitive load theory & 1 & $\begin{array}{l}\text { Describes the human cognitive architecture and the need to apply sound instructional design based on knowledge of } \\
\text { working memory, long-term memory and cognitive schemas }\end{array}$ \\
\hline
\end{tabular}

consensus about how it influences their approach to the use of social media in medical education. We also found that there was a high degree of consensus on both Social Development Theory and Communities of Practice. These latter two theories as well as Discovery Learning and Cognitive Apprenticeship all fall under the construct of Constructivist Learning Theory, as described below.

\section{DISCUSSION}

In this study we examined the conceptual frameworks of medical educators using social media and explored how this mapped to learning theories. We found that these frameworks did map to learning theories, with a strong consensus that Connectivism, Social Development Theory and Communities of Practice learning theories were aligned best with their practices. One of the important implications of our findings is that future education and research may be best served by focusing on these learning theories as we continue to introduce social media into medical education.

Traditionally, learning theories tend to be clustered in three large categories: behaviourist, cognitivist and constructivist. ${ }^{12}$ In short, behaviourist theories are those that propose that knowing is the result of objective experience; cognitivist theories are those that propose that knowing is the outcome of mental processing; and constructivist theories are those that propose that knowing is subjectively constructed (table 2).

In the age of technology, learning theories have shifted from behaviourist to constructivist. ${ }^{13}$ This is certainly evidenced in the results of this work (see table 1). There were no behaviourist theories put forward as reflecting the philosophy of the workshop participants. Of the seven proposed learning theories that capture and represent the philosophy of these medical educators, four were learning theories that are considered to be within the paradigm of Constructivist Learning Theory- namely, Social Development Theory, Communities of Practice, Discovery Learning and Cognitive Apprenticeship. The concepts that were common to their philosophical approach to education and that weave through these constructivist theories are that of the belief that knowledge is subjectively constructed, primarily within a social context. Learners learn from those with more expertise than themselves. This may be the instructor, but also may be from other more knowledgeable peers. Learning is a social process whereby students learn best when they actively construct their own knowledge, understanding and meaning through interaction with their peers. ${ }^{14}$

Further, in constructivist theories, the focus is on the learner and the process of learning versus the transmission of information from the instructor. It is presumed that learners bring pre-existing knowledge and experience to a learning situation. The learners are encouraged to take responsibility for their learning and to assume a reflective stance to it. The teacher's responsibility is to facilitate the learning process. This occurs through the purposeful design and structure of the curriculum and learning activities. ${ }^{14}$

The learning environment is considered to be a critical piece of a constructivist approach whereby the learners are provided with the tools, resources and support needed to build their own knowledge. Scaffolding is provided to learners: support that is greater at the outset of learning situations and fades as the learner develops his or her own knowledge and expertise. The learning environment is flexible and has the capability to adapt to the individual's learning needs. However, the learning environment should also reflect the context and the complexities of the practice. ${ }^{15}$

Although Self-Determination Theory is considered to be a motivation theory, "theories of learning typically treat motivation as a concept that is an adjunct to the principles for generating learning". " Motivational perspectives on learning consider the educational environment, the teacher's responses to the learners' efforts, the social context for learning and the learners' degree of

Table 2 Three approaches to learning ${ }^{12}$

\begin{tabular}{|c|c|c|c|}
\hline & Behaviourism & Cognitivism & Constructivism \\
\hline Learning is achieved through... & Transmitted information & Acquisition of knowledge & Construction of knowledge \\
\hline Learning is believed to be ... & A change in behaviour & Built on previously learned materials & A change in meaning \\
\hline Teaching is ... & Instructor-centered & Instructor-centered & Student-centered \\
\hline Process of learning & Passive & Active & Active \\
\hline
\end{tabular}


engagement in the activities as the aspects of teaching and learning that stimulate or inhibit motivation. These same elements are those promulgated in Constructivist Learning Theory.

There is a similar relationship between Connectivism and Constructivism. The entire group came to a consensus on Connectivism as a learning theory that was relevant and reflected their approach to using social media in their teaching and learning activities. Connectivism is particularly relevant and applicable as a learning theory to inform the use of social media in medical education because it is a theory that has been developed specifically to conceptualise learning in a technological context. It therefore also holds strong implications for teaching in a technological era. Importantly, despite the fact that Connectivism is a very new theory based on the use of technology in education, there are themes of Connectivism that mirror the themes articulated above regarding the constructivist theories-namely, that learning is social, learning is an active process, learning requires reflection and learning occurs in a particular context. Indeed, although Siemens has argued that Connectivism is a new category of learning theory, it has been included within the constructivist paradigm at http://www. learningtheories.com. The concept that is quite unique to Connectivism is that how people learn, work and function is altered by the technology that is being used. Therefore, educators must recognise the impact of these learning tools in order to adequately prepare learners to flourish in a digital era. ${ }^{16}$

The one theory that may appear to be the outlier is that of Cognitive Load Theory. However, upon serious consideration of the theories outlined above, it becomes clear that it sits in a position that aligns with the connectivist theoretical frame. It specifically identifies that an individual's working memory is limited and that information must be transferred to long-term memory. Although theoretically it is proposed that the long-term memory has unlimited capacity, it was developed in the 1980s, prior to the widespread adoption of computers and what has been described as the 'information explosion'. The concept of the importance of designing instructional activities in a manner that facilitates the organisation of knowledge into schemas is similar to the connectivist principle of the ability to connect between fields, ideas and concepts as a core skill. This, paired with the thought in Cognitive Load Theory that it is important to have ready access to previously stored information, is very much in keeping with the connectivist principle of learning as a process of the connection of information sources.

The findings of the workshop identified more than one educational theory that informs the use of social media in medical education. This finding is in keeping with that of others who have stated that it is not necessary or reasonable to imagine that one theory would suffice, as there are many different kinds of learning theory and each emphasises a different aspect of learning. ${ }^{17}$ This is useful for educators when considering different purposes. The results of this project demonstrate the marked harmony between the multiple theories that were selected as representative of a theoretical basis upon which to use social media in education. In the connectivist literature, Frances Bell states, "There is an argument that theories can be complementary". ${ }^{18}$

Using social media in teaching provides instructors with the opportunity to implement constructivist and connectivist learning theory in creative and innovative ways. Social media can be used to connect the learners to each other to increase the social potential for learning, enhance learning from peers, share content, connect outside the classroom, easily exchange ideas, create a community of practice and connect with content experts. Scaffolding is applied as the teacher's participation is more intensive at the outset and diminishes as the learners engage in more group work and advanced problem solving. The teacher can provide guidance for self-directed learning, opportunities for the learner to engage in reflective thought and the creation of a flexible learning environment incorporating authentic context by using problem-based and case-based material to build collective resources and share best practices.

Throughout this study we identified several limitations. First, the participants in this workshop self-selected for their interest in this topic and hence may not fully represent all those in medical education who are applying social media. Second, the results of the workshop were achieved by consensus, not a formal quantitative or qualitative analysis. Finally, there was considerable variation in understanding of learning theory expressed by workshop participants.

Based on the findings of this study, we recommend that educators who are using social media should have an understanding of Connectivism and Constructivism. The use of learning theory will assist them in designing effective learning events, curricula

\section{Main messages}

Medical educators using social media identify with connectivism and constructivism learning theories.

- There is little evidence in the literature that learning theory is being formally applied to the use of social media.

- Formal education on learning theory may further enhance the use of social media.

\section{Current research questions}

To what degree does the formal teaching of learning theory enhance the application of social media in medical education?

- Are certain learning theories better suited to specific applications of social media?

- How can we define and measure success in the use of social media in medical education?

\section{Key references}

- McGee JB, Begg M. What medical educators need to know about "Web 2.0." Med Teach 2008;30:164-9.

- Cheston CC, Flickinger TE, Chisolm MS. Social media use in medical education: a systematic review. Acad Med 2013;88:893-901.

- Hollinderbaumer A, Hartz T, Uckert F. Education 2.0-how has social media and Web 2.0 been integrated into medical education? A systematical literature review. GMS Z Med Ausbild 2013;30:Doc14.

- Bordage G. Conceptual frameworks to illuminate and magnify. Med Educ 2009;43:312-19.

- Melrose $S$. Constructivism: learning by forming connections. In: Melrose S, Park C, Perry B, eds. Teaching health professionals online: frameworks and strategies. Edmonton, AB: AU Press, Athabaska University, 2013. 
and assessment practices and hence to improve learning. An important intervention would be to provide formal education to a cohort of medical educators on these learning theories. They could then apply these theories in a more deliberate fashion to the use of social media.

Twitter Follow Leslie Flynn at @flynnlv

Acknowledgements The authors wish to acknowledge the participants in the consensus conference for their contributions to developing the recommendations.

Contributors The conception or design of the work was performed by $L F, A J$ and KAM. The acquisition and analysis of the data was performed by LF and AJ. The manuscript was drafted by LF and revised critically by LF, AJ and KAM. All authors approved the final version of the manuscript.

Competing interests None declared.

Ethics approval Ethics approval was received from the Health Sciences Research Ethics Board at Queen's University.

Provenance and peer review Commissioned; externally peer reviewed.

\section{REFERENCES}

1 Chu LF, Erlendson MJ, Sun JS, et al. Information technology and its role in anaesthesia training and continuing medical education. Best Pract Res Clin Anaesthesiol 2012;26:33-53.

2 McGee JB, Begg M. What medical educators need to know about "Web 2.0". Med Teach 2008:30:164-9.

3 O'Reilly T. What is Web 2.0: Design Patterns and Business Models for the Next Generation of Software. 2005. http://www.oreillynet.com/pub/a/oreilly/tim/news/ 2005/09/30/what-is-web-2.0.html (accessed 3 Dec 2014).

4 Bahner DP, Adkins E, Patel N, et al. How we use social media to supplement a novel curriculum in medical education. Med Teach 2012;34:439-44.

5 Cheston CC, Flickinger TE, Chisolm MS. Social media use in medical education: a systematic review. Acad Med 2013;88:893-901.
6 Hollinderbaumer A, Hartz T, Uckert F. Education 2.0-how has social media and Web 2.0 been integrated into medical education? A systematical literature review. GMS Z Med Ausbild 2013;30:Doc14.

7 Wang AT, Sandhu NP, Wittich CM, et al. Using social media to improve continuing medical education: a survey of course participants. Mayo Clin Proc 2012;87:1162-70.

8 Gikas J, Grant MM. Mobile computing devices in higher education: Student perspectives on learning with cellphones, smartphones \& social media. Internet Higher Educ 2013;19:18-26.

9 Gredler ME. Cognitive models and a theory of academic motivation. In: Learning and instruction: theory into practice. 6th edn. Boston, MA: Pearson Education, 2009:391-431.

10 Bordage G. Conceptual frameworks to illuminate and magnify. Med Educ 2009:43:312-19.

11 Reigeluth CM, Carr-Chellman AA. Instructional-design theories and models, Volume III: Building a common knowledge base. New York and London: Routledge, Taylor \& Francis Group, 2009.

12 Lowerison G, Cote R. Revisiting learning theory for e-learning. In: Carliner S, Shank $P$, eds. The e-learning handbook. San Francisco, CA: John Wiley \& Sons, 2008:423-58.

13 Jonassen DH, Reeves TC. Learning with technology: using computers as cognitive tools. In: Jonassen DH, ed. Handbook of research for educational communications and technology. New York, NY: Macmillan, 1996:693-719.

14 Sthapornnanon N, Sakulbumrungsil R, Theeraroungchaisri A, et al. Social constructivist learning environment in an online professional practice course. Am J Pharm Educ 2009;73:10.

15 Melrose S. Constructivism: learning by forming connections. In: Melrose S, Park C, Perry B, eds. Teaching health professionals online: frameworks and strategies. Edmonton, AB: AU Press, Athabaska University, 2013:63-87.

16 Siemens G. Connectivism: a learning theory for the digital age. Int I Instr Technol Distance Learn 2005;2:1.

17 Wenger E. Communities of practice: learning, meaning, and identity. Cambridge, UK: Cambridge University Press, 1998.

18 Bell F. Connectivism: its place in theory-informed research and innovation in technology-enabled learning. Int Rev Res Open Distance Learn 2011;12:3. 